\title{
Serum Levels of Soluble P-Selectin Are Increased and Associated With Disease Activity in Patients With Behçet's Syndrome
}

\author{
Yusuf Turkoz, ${ }^{1}$ Cem Evereklioglu, ${ }^{2}$ Abdullah Özkiriş, ${ }^{2}$ Selçuk Mistik, ${ }^{3}$ \\ Murat Borlu, ${ }^{4}$ Ibrahim H. Özerol, ${ }^{5}$ Fuat Duygulu, ${ }^{6}$ and Özgür Ilhan ${ }^{2}$ \\ ${ }^{1}$ Department of Biochemistry, Inönü University Medical Faculty, Turkey \\ ${ }^{2}$ Department of Ophthalmology, Erciyes University Medical Faculty, Turkey \\ ${ }^{3}$ Department of Family Medicine, Erciyes University Medical Faculty, Turkey \\ ${ }^{4}$ Department of Dermatology, Erciyes University Medical Faculty, Turkey \\ ${ }^{5}$ Department of Microbiology, Inönü University Medical Faculty, Turkey \\ ${ }^{6}$ Department of Orthopaedics and Traumatology, Erciyes University Medical Faculty, Turkey
}

Received 22 February 2005; accepted 18 April 2005

\begin{abstract}
Behçet's syndrome (BS) is a relapsing, chronic, inflammatory disease characterized by endothelial dysfunction, atherothromboembogenesis, and leukocytoclastic vasculitis with complex immunologic molecular interactions. Generalized derangements of the lymphocyte and neutrophil populations, activated monocytes, and increased PMNLs motility with upregulated cell surface molecules such as ICAM-1, VCAM-1, and E-selectin, which are found on the endothelial cells, leukocytes, and platelets, have all been demonstrated during the course of BS. Our aim is to investigate the association of serum concentrations of soluble P-selectin in patients with BS, and to evaluate whether disease activity has an effect on their blood levels. This multicenter study included 31 patients with BS (15 men and 16 women) and 20 age- and sex-matched healthy control volunteers (11 men and nine women). Neutrophil count, erythrocyte sedimentation rate, and acute-phase reactants as well as soluble P-selectin levels were determined. The mean age and sex distributions were similar $(P>.05)$ between BS patients (35 years) and control volunteers $(36$ years). Serum levels of soluble P-selectin in patients with BS $(399 \pm 72 \mathrm{ng} / \mathrm{mL})$ were significantly $(P<.001)$ higher when compared with control subjects $(164 \pm 40 \mathrm{ng} / \mathrm{mL})$. In addition, active BS patients $(453 \pm 37 \mathrm{ng} / \mathrm{mL})$ had significantly $(P<.001)$ elevated levels of soluble P-selectin than those in inactive period $(341 \pm 52 \mathrm{ng} / \mathrm{mL})$. This study clearly demonstrated that serum soluble P-selectin levels are increased in BS patients when compared with control subjects, suggesting a modulator role for soluble P-selectin during the course of platelet activation and therefore, atherothrombogenesis formation in BS, especially in active disease.
\end{abstract}

\section{INTRODUCTION}

Behçet's syndrome (BS) is a chronic and inflammatory disease which involves multiple organs with a generalized vasculitis of arteries and veins [1]. This chronic disease was first described by Hulusi Behçet in 1937 [2]. Oral apthae, genital ulcers, and ocular involvement mainly as uveitis are the classical signs of the disease. However, every organ in the body could be affected by BS $[1,3,4,5,6]$. The prevalence of $\mathrm{BS}$ is as high as $1 / 1000$ in Mediterranean (Turkey) and Middle and Far East countries (Japan) $[7,8,9]$. Although there is no proven causative agent, viral infections, immune disorders, genetic predisposition, and environmental factors have been proposed as etiologic

Correspondence and reprint requests to Cem Evereklioglu, Department of Ophthalmology, Erciyes University Medical Faculty, Turkey; evereklioglu@hotmail.com factors [7]. Endothelial dysfunction causes vasculitis and thrombosis in BS [10]. International Study Group have defined the criterion for the diagnosis of BS in 1990 [11]. Major challenge in the management of patients with BS is lack of clear notion of etiopathogenesis. Moreover, therapeutic approaches are based on assumptions rather than proven mechanisms of the disease.

Selectins are found on endothelial cells, leukocytes, and platelets [12]. There are three types of selectins, namely, E-, L-, and P-selectins [13]. These cell surface glycoproteins are thought to promote inflammatory reactions by facilitating leukocyte recruitment [14]. Activated platelets express P-selectin, which binds to P-selectin glycoprotein ligand 1 (PSGL-1). This interaction is responsible for the recruitment of inflammatory leukocytes to thrombi [15].

Because of its impacts on endothelial cells with its effect on leukocytes, we aimed to investigate serum levels of soluble P-selectin during the course of BS. Our hypothesis 
is that soluble P-selectin could be important during the inflammatory process of the disease course. Therefore, the aims of this study were (1) to investigate the association of serum soluble P-selectin concentrations in patients with BS and (2) to evaluate whether disease activity has an effect on the blood soluble P-selectin concentration.

\section{PATIENTS AND METHODS}

This multicenter study included 31 patients with Behçet's syndrome and 20 age- and sex-matched healthy control volunteers. Subjects with hepatic or renal diseases, diabetes, essential hypertension, and pregnancies were excluded from the study. Detailed history of drugs used was obtained in both groups. The diagnosis of uveitis was made according to the International Study Group criteria [16] and informed consent was obtained from all subjects in both groups.

Both clinical and laboratory findings were used to determine disease activity. Clinically, worsening of clinical symptoms on admission with having at least two of the 5 major symptoms according to the ISG criteria was considered to be in the exacerbation stage of the disease. Inactive patients had no symptoms or signs of disease activity at least two months before admission. In laboratory investigations, ESR, neutrophil count, and acute-phase reactants were investigated $[17,18]$.

\section{Neutrophil count, ESR, and acute-phase reactants analyses}

In all subjects, antecubital whole blood samples (total $5 \mathrm{~mL}$ ) were obtained by venipuncture from an antecubital vein, avoiding haemolysis, into plain tubes during resting position after an overnight fast and 30 minutes of supine rest. None of the subjects in both groups was receiving any topical or systemic medication on admission. Both the technician taking the blood and the analyser were blinded to the group of the subject. The first half of the blood samples $(2.5 \mathrm{~mL})$ was centrifuged at $800 \mathrm{x}$ gravity for $10 \mathrm{~min}-$ utes, and then serum was separated and kept at $-70^{\circ} \mathrm{C}$ until time of analysis.

Second half of the blood samples $(2.5 \mathrm{~mL})$ with EDTA $(1 \mathrm{mg} / \mathrm{mL})$ anticoagulant was used for the neutrophil counting by an automated blood counter (Coulter-STKS, Luton, UK). $\alpha_{1}$-antitrypsin and $\alpha_{2}$ macroglobulin concentrations were measured in the serum by Behring nephelometer 100 analyser. The ESR was determined by the classical Westergren method [19, $20,21]$.

\section{Soluble P-selectin analysis}

Blood samples were taken by venopuncture from the patients with BS and 20 healthy individuals and allowed to clot for 15 minutes on ice before centrifugation and serum was stored at $-40^{\circ} \mathrm{C}$ until analysis. Human serum P-selectin levels were measured by soluble
P-selectin enzyme-linked immunosorbent assay kit (Bender MedSystems, Vienna, Austria). ELISA assay was carried out on diluted samples following manufacturer's instructions. Assay range of the sP-selectin kit was 1-140 ng sP-selectin/mL and minimal detection limit was approximately $1.0 \mathrm{ng} / \mathrm{mL}$. The intraassay and interassay coefficients of variation for the assay were $5 \%$ and $8 \%$, respectively.

\section{Statistical analysis}

The Mann-Whitney $U$ test was used for analysis and the results were expressed as mean \pm SD with range. Statistical Package for the Social Sciences for Windows (SPSS Inc., version 8.0, Chicago, Ill, USA) was used for statistical analysis and $P<.05$ was considered to be significant.

\section{RESULTS}

Behçet's syndrome patients were consisted of 15 men and 16 women (mean age $=35$ years) and there were 11 men and 9 women in the age- and sex-matched healthy control volunteers (mean age $=36$ years). Oral aphthae were present in all cases (100\%). Seventeen patients $(54.8 \%)$ had bilateral ocular disease (anterior hypopyon uveitis, iridocyclitis, retinal vasculitis, vitritis, or panuveitis). Twenty-nine cases $(93.5 \%)$ had various skin lesions, 27 patients $(87.0 \%)$ had articular symptoms, and 24 patients $(77.4 \%)$ had genital ulcers. Sixteen cases $(51.6 \%)$ demonstrated positive pathergy test. Gastrointestinal system symptoms were present in 4 cases $(12.9 \%)$ and neurological disease in 1 case $(0.3 \%)$.

The mean disease duration for Behçet's patients was 10 years. The differences for the ages between the groups were similar (for each group, $P>.05$ ). Active patients had significantly higher values for acute-phase reactants when compared with inactive patients and control volunteers (for each, $P<.01$ ) (see Table 1 ). Serum levels of soluble P-selectin in patients with BS $(399 \pm 72 \mathrm{ng} / \mathrm{mL})$ were significantly $(P<.001)$ higher when compared with control subjects $(164 \pm 40 \mathrm{ng} / \mathrm{mL})$. In addition, active BS patients $(453 \pm 37 \mathrm{ng} / \mathrm{mL})$ had significantly $(P<.001)$ elevated levels of soluble P-selectin than those in inactive period $(341 \pm 52 \mathrm{ng} / \mathrm{mL})$ of the disease (see Figure 1).

\section{DISCUSSION}

Selectins are adhesion molecules regulating interactions of the leukocytes, platelets, and endothelial cells [13]. These molecules are involved in leukocyte migration and inflammation by regulating the interactions of the leukocytes with endothelium, which are essential components of the immune response [22]. Circulating leukocytes bind to the selectins expressed by activated endothelium and thereby leukocyte migration occurs [23].

On the other hand, selectins are molecules involved in chronic and acute inflammation process. They are found 
TABLE 1. The levels of acute-phase reactants in patients with active or inactive patients with Behçet's syndrome and healthy control volunteers. (BS denotes Behçet's syndrome.)

\begin{tabular}{|c|c|c|c|}
\hline & $\begin{array}{c}\text { Active BS } \\
(n=16) \\
\text { Mean } \pm \text { SD }\end{array}$ & $\begin{array}{l}\text { Inactive BS } \\
\quad(n=15) \\
\text { Mean } \pm \text { SD }\end{array}$ & $\begin{array}{c}\text { Controls } \\
(n=20) \\
\text { Mean } \pm \text { SD }\end{array}$ \\
\hline Mean age (years) & $35 \pm 11$ & $34 \pm 10$ & $36 \pm 9$ \\
\hline Soluble P-selectin (ng/mL) & $453 \pm 37^{*}$ & $341 \pm 52^{\dagger}$ & $164 \pm 40$ \\
\hline Neutrophil count $\left(\times 10^{3} / \mathrm{mL}\right)$ & $5 \pm 1^{*}$ & $3 \pm 0.6$ & $3 \pm 0.3$ \\
\hline Erythrocyte sedimentation rate $(\mathrm{mm} / 1 \mathrm{~h})$ & $35 \pm 7^{*}$ & $22 \pm 6^{\dagger}$ & $9 \pm 1$ \\
\hline$\alpha_{1}$-antitrypsin $(\mathrm{mg} / \mathrm{dL})$ & $208 \pm 56^{*}$ & $164 \pm 49^{\dagger}$ & $134 \pm 18$ \\
\hline$\alpha_{2}$-macroglobulin $(\mathrm{mg} / \mathrm{dL})$ & $269 \pm 31^{*}$ & $211 \pm 23^{\dagger}$ & $158 \pm 25$ \\
\hline
\end{tabular}

* Significantly different from the inactive patients and controls by Mann-Whitney $U$ test (for each, $P<.01$ ).

† Significantly different from the controls by Mann-Whitney $U$ test (for each, $P<.01$ ).

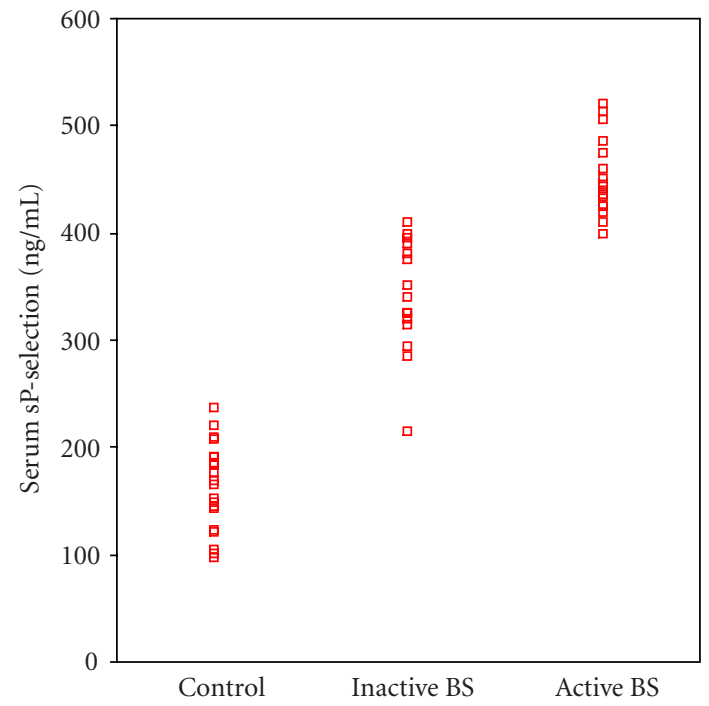

Figure 1. The distribution of serum sP-selectin levels against disease activity in patients with active BS and inactive BS.

to be effective in postischemic inflammation in muscle, kidney, and heart, skin inflammation, atherosclerosis, glomerulonephritis, and luphus erythematosus [12]. The major role of inflammation in atherosclerosis has forwarded researchers to investigate selectin levels in coronary syndromes. Soluble P-selectin was shown to increase in patients with unstable angina and myocardial infarction $[24,25,26]$. Elevated levels of soluble P-selectin have been reported in pulmonary arterial hypertension [27], chronic heart failure [28], and cyanotic congenital heart disease [29] as well. Concerning the role of soluble Pselectin in rheumatological diseases, Ateş et al [30] have reported that serum soluble P-selectin levels were not significantly different among patients with rheumatoid arthritis and systemic sclerosis.

Because there is not any definitive and specific therapy of BS $[31,32]$ and it affects every organ in the body with no exceptions $[1,3,4,5,6]$, there is probably a molecule or a group of molecules affecting the human body in general. In addition, these molecules could start a generalized inflammation in BS patients. Moreover, these molecules taking part in the etiopathogenesis of BS should have the potential effect of causing venous thrombosis. Endothelial dysfunction is the most prominent feature of BS and is observed even in patients without any clinical vascular involvement $[33,34,35]$. The pathogenesis of BS is closely related to endothelial cells, leukocyte functions, and autoimmunity, and previous studies have investigated selectin adhesion molecules (P- and E-selectin) in the circulation [36]. It has been demonstrated that all of the adhesion molecules were increased in serum from patients with BS compared with controls. In addition, serum levels of E-selectin were prominently increased during the active stage of the disease, indicating the presence of immune system activation and endothelial injury in BS [37]. Furthermore, the expression of $\mathrm{E}$ - and L- selectin on the endothelial and inflammatory cells by immunohistochemistry in erythema nodosum lesions taken from 15 patients with BS has been demonstrated previously [38].

In the present study, we aimed to investigate serum soluble P-selectin concentrations in patients with BS and to evaluate the relation of serum soluble P-selectin levels with disease activity. We demonstrated (1) an increase in serum soluble P-selectin levels in patients with BS and (2) increased concentrations of soluble P-selectin levels in patients with active BS. Depending on these results, it is possible that soluble P-selectin may take a role in the pathophysiology of vascular lesions, and therefore inflammatory reactions by facilitating leukocyte recruitment. An association of soluble P-selectin with proinflammatory cytokines can be suggested, as increased levels of soluble $\mathrm{P}$-selectin is correlated with the activity of BS.

P-, E-, and L-selectins are members of the selectin adhesion molecule family [13]. E-selectin is expressed by activated endothelial cells. P-selectin is constitutively synthesized and stored within the granules of platelets and 
is redistributed to the plasma membrane upon activation of these cells. L-selectin, however, is expressed on the leukocyte surface. These adhesion molecules can be used as activation markers of endothelium (E-selectin and possibly P-selectin), platelets (P-selectin), and leukocytes (L-selectin). The main role of these adhesion molecules is closely related to the immunological response of the regulation of leukocyte trafficking. P-selectin also has additional specific roles in the inflammatory and homeostatic functions of the platelets [13]. The characteristic pathological finding is a multifocal necrotizing vasculitis with lymphotic infiltration of the veins, capillaries, and arteries. Up to $25 \%$ of BS patients suffer from systemic venous thrombosis [3, 39]. In the light of this knowledge, soluble P-selectin may participate during the course of inflammatory and thrombotic vasculitis events during the course of BS because an activated hemostatic system with an increased arterial and venous thrombotic tendency are among the clinical features of BD. In the previous studies on the levels of selectins in BS, Haznedaroglu et al [36] have reported that more prominent increases in selectin levels in patients with extensive BS suggest that circulating selectin concentrations are related to disease severity [36]. In contrast, Nagahama et al [40] have found no elevations for sP-selectin levels in patients with BS.

In conclusion, this study clearly demonstrated that serum soluble P-selectin levels are increased in BS patients when compared with control subjects, suggesting a modulator role of soluble P-selectin in BS. In addition, patients with active BS had significantly higher serum soluble P-selectin levels than remaining BS patients. Therefore, serum levels of soluble P-selectin may provide a useful marker for vascular inflammatory diseases and may possibly be used for both diagnosis and estimation of disease activity in BS patients.

\section{ACKNOWLEDGMENT}

Authors have no financial or proprietary interest in any instrument or products used in this study.

\section{REFERENCES}

[1] Rizzi R, Bruno S, Dammacco R. Behçet's disease: an immune-mediated vasculitis involving vessels of all sizes. Int J Clin Lab Res. 1997;27(4):225-232.

[2] Behçet H. Uber rezidiverende aphthose, durch ein virus verursachte Geschwure am Mund, am Auge und an den Genitalien. Dermatol Wochenschr. 1937;105:1152-1157.

[3] Sakane T, Takeno M, Suzuki N, Inaba G. Behçet's disease. N Engl J Med. 1999;341(17):1284-1291.

[4] Gunen H, Evereklioglu C, Kosar F, Er H, Kizkin O. Thoracic involvement in Behçet's disease and its correlation with multiple parameters. Lung. 2000;178(3):161-170.
[5] Evereklioglu C, Cokkeser Y, Doganay S, Er H, Kizilay A. Audio-vestibular evaluation in patients with Behçet's syndrome. J Laryngol Otol. 2001;115(9):704-708.

[6] Kaneko F, Takahashi Y, Muramatsu Y, Miura Y. Immunological studies on aphthous ulcer and erythema nodosum-like eruptions in Behçet's disease. Br J Dermatol. 1985;113(3):303-312.

[7] Ghate JV, Jorizzo JL. Behçet's disease and complex aphthosis. J Am Acad Dermatol. 1999;40(1):1-18.

[8] Dilsen N. History and development of Behçet's disease. Rev Rhum Engl Ed. 1996;63(7-8):512-519.

[9] Lee LA. Behçet disease. Semin Cutan Med Surg. 2001;20(1):53-57.

[10] Evereklioglu C, Turkoz Y, Er H, Inaloz HS, Ozbek $\mathrm{E}$, Cekmen M. Increased nitric oxide production in patients with Behçet's disease: is it a new activity marker? J Am Acad Dermatol. 2002;46(1):50-54.

[11] International Study Group for Behçet's Disease. Criteria for diagnosis of Behçet's disease. Lancet. 1990;335(8697):1078-1080.

[12] Ley K. The role of selectins in inflammation and disease. Trends Mol Med. 2003;9(6):263-268.

[13] Kansas GS. Selectins and their ligands: current concepts and controversies. Blood. 1996;88(9):32593287.

[14] Wynn TA, Hesse M, Sandler NG, et al. P-selectin suppresses hepatic inflammation and fibrosis in mice by regulating interferon gamma and the IL-13 decoy receptor. Hepatology. 2004;39(3):676-687.

[15] Larsen E, Celi A, Gilbert GE, et al. PADGEM protein: a receptor that mediates the interaction of activated platelets with neutrophils and monocytes. Cell. 1989;59(2):305-312.

[16] Bloch-Michel E, Nussenblatt RB. International Uveitis Study Group recommendations for the evaluation of intraocular inflammatory disease. Am J Ophthalmol. 1987;103(2):234-235.

[17] Evereklioglu C, Yurekli M, Er H, et al. Increased plasma adrenomedullin levels in patients with Behçet's disease. Dermatology. 2000;201(4):312-315.

[18] Evereklioglu C, Inaloz HS, Kirtak N, et al. Serum leptin concentration is increased in patients with Behçet's syndrome and is correlated with disease activity. Br J Dermatol. 2000;147(2):331-336.

[19] Erkiliç K, Evereklioglu C, Çekmen M, Ozkiris A, Duygulu F, Dogan H. Adenosine deaminase enzyme activity is increased and negatively correlates with catalase, superoxide dismutase and glutathione peroxidase in patients with Behçet's disease: original contributions/clinical and laboratory investigations. Mediators Inflamm. 2003;12(2):107-116.

[20] Evereklioglu C, Çekmen M, Özkiriş A, Karabaş L, Çaliş M. The pathophysiological significance of red blood cell nitric oxide concentrations in inflammatory Behçet's disease. Mediators Inflamm. 2003;12(4):255-256. 
[21] Evereklioglu C, Er H, TürkÖz Y, Çekmen M. Serum levels of TNF- $\alpha$, sIL-2R, IL-6, and IL-8 are increased and associated with elevated lipid peroxidation in patients with Behçet's disease. Mediators Inflamm. 2002;11(2):87-93.

[22] Palabrica T, Lobb R, Furie BC, et al. Leukocyte accumulation promoting fibrin deposition is mediated in vivo by P-selectin on adherent platelets. Nature. 1992;359(6398):848-851.

[23] van de Kerkhof PC, Rulo HF, van Pelt JP, van Vlijmen-Willems IM, De Jong EM. Expression of endoglin in the transition between psoriatic uninvolved and involved skin. Acta Derm Venereol. 1998;78(1):19-21.

[24] Ikeda H, Nakayama H, Oda T, et al. Soluble form of P-selectin in patients with acute myocardial infarction. Coron Artery Dis. 1994;5(6):515-518.

[25] Gurbel PA, Serebruany VL. Myths and realities of Pselectin plasma levels in patients with acute myocardial infarction. Thromb Res. 1997;88(3):343-344.

[26] Shimomura H, Ogawa H, Arai H, et al. Serial changes in plasma levels of soluble P-selectin in patients with acute myocardial infarction. Am J Cardiol. 1998;81(4):397-400.

[27] Sakamaki F, Kyotani S, Nagaya N, et al. Increased plasma P-selectin and decreased thrombomodulin in pulmonary arterial hypertension were improved by continuous prostacyclin therapy. Circulation. 2000;102(22):2720-2725.

[28] Chin BS, Chung NA, Gibbs CR, Blann AD, Lip GY. Vascular endothelial growth factor and soluble Pselectin in acute and chronic congestive heart failure. Am J Cardiol. 2002;90(11):1258-1260.

[29] Horigome H, Murakami T, Isobe T, Nagasawa T, Matsui A. Soluble P-selectin and thrombomodulinprotein C-Protein S pathway in cyanotic congenital heart disease with secondary erythrocytosis. Thromb Res. 2003;112(4):223-227.

[30] Ates A, Kinikli G, Turgay M, Duman M. Serumsoluble selectin levels in patients with rheumatoid arthritis and systemic sclerosis. Scand I Immunol. 2004;59(3):315-320.

[31] Evereklioglu C. Managing the symptoms of Behçet's disease. Expert Opin Pharmacother. 2004;5(2):317328.

[32] Evereklioglu C. Current concepts in the etiology and treatment of Behçet's disease. Surv Ophthalmol. 2005;50(4):297-350.

[33] Schmitz-Huebner U, Knop J. Evidence for an endothelial cell dysfunction in association with Behçet's disease. Thromb Res. 1984;34(4):277-285.

[34] Haznedaroglu IC, Ozdemir O, Ozcebe O, Dundar SV, Kirazli S. Circulating thrombomodulin as a clue of endothelial damage in Behçet's disease. Thromb Haemost. 1996;75:974-975.

[35] Haznedaroglu IC, Ozcebe OI, Ozdemir O, Celik I, Dundar SV, Kirazli S.Impaired haemostatic kinetics and endothelial function in Behçet's disease. J Intern Med. 1996;240(4):181-187.

[36] Haznedaroglu E, Karaaslan Y, Buyukasik Y, et al. Selectin adhesion molecules in Behçet's disease. Ann Rheum Dis. 2000;59(1):61-63.

[37] Kosar A, Haznedaroglu S, Karaaslan Y, et al. Effects of interferon-alpha2a treatment on serum levels of tumor necrosis factor-alpha, tumor necrosis factoralpha2 receptor, interleukin-2, interleukin-2 receptor, and E-selectin in Behçet's disease. Rheumatol Int. 1999;19(1-2):11-14.

[38] Senturk T, Aydintug O, Kuzu I, et al. Adhesion molecule expression in erythema nodosumlike lesions in Behçet's disease. A histopathologi$\mathrm{cal}$ and immunohistochemical study. Rheumatol Int. 1998;18(2):51-57.

[39] Lakhanpal S, Tani K, Lie JT, Katoh K, Ishigatsubo Y, Ohokubo T. Pathologic features of Behçet's syndrome: a review of Japanese autopsy registry data. Hum Pathol. 1985;16(8):790-795.

[40] Nagahama M, Nomura S, Ozaki Y, Yoshimura C, Kagawa H, Fukuhara S. Platelet activation markers and soluble adhesion molecules in patients with systemic lupus erythematosus. Autoimmunity. 2001;33(2):85-94. 


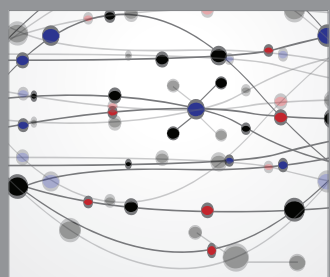

The Scientific World Journal
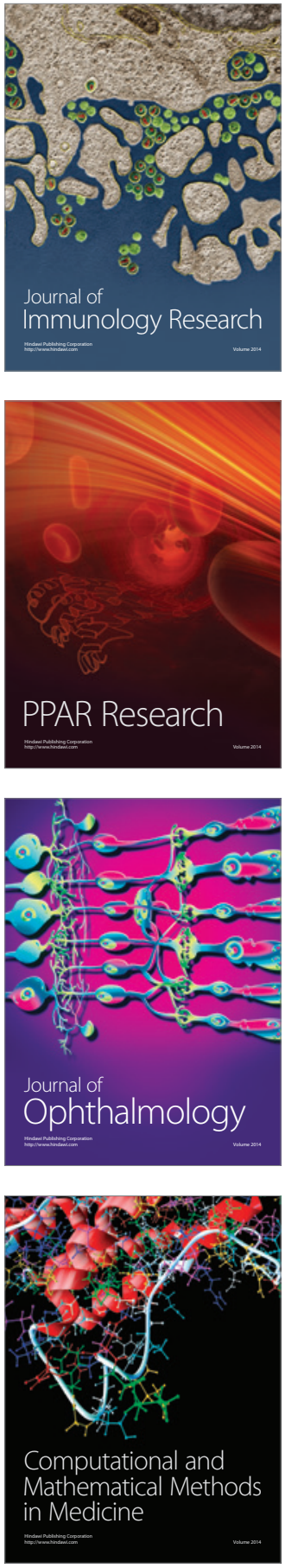

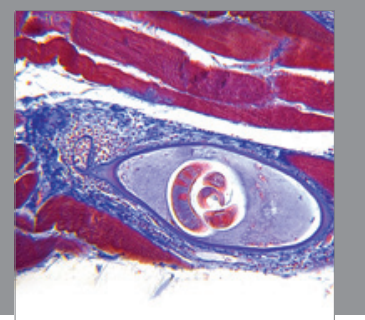

Gastroenterology

Research and Practice
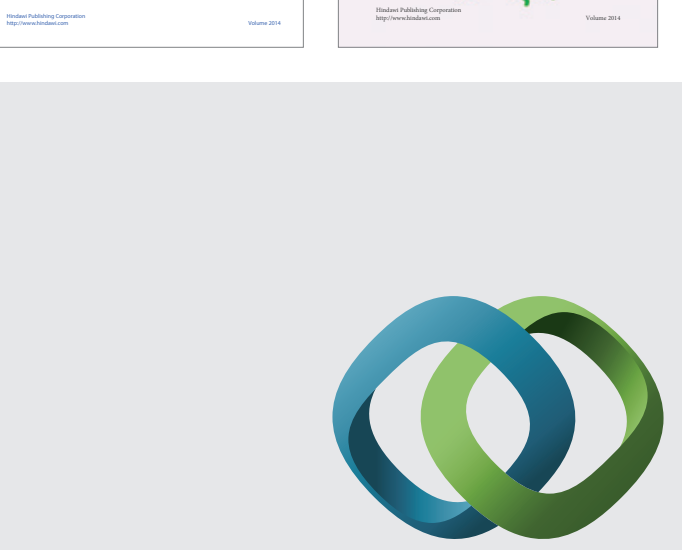

\section{Hindawi}

Submit your manuscripts at

http://www.hindawi.com
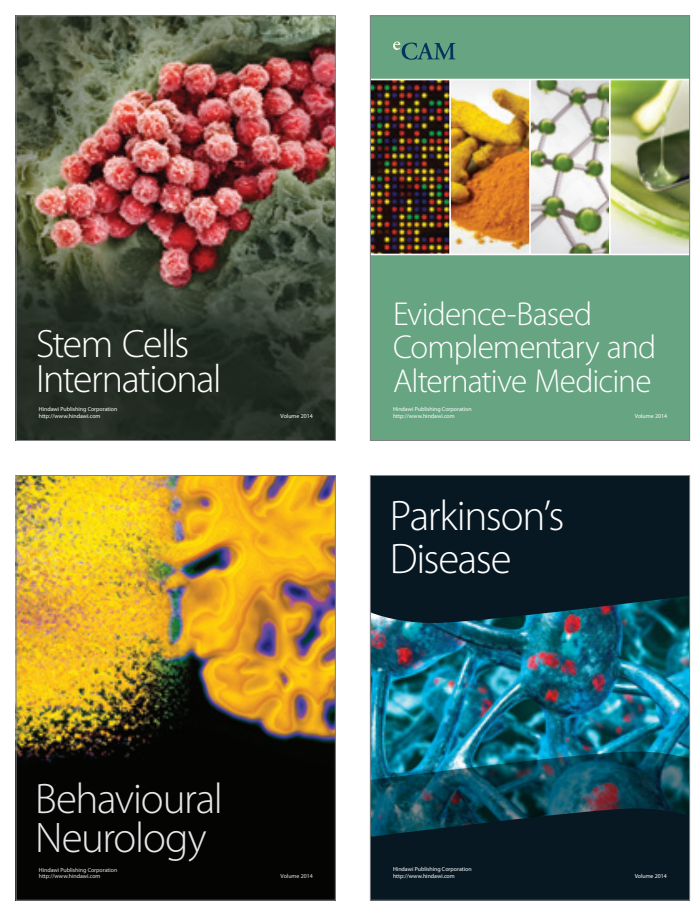

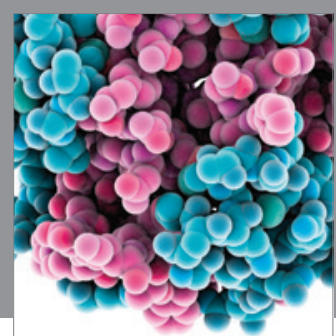

Journal of
Diabetes Research

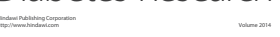

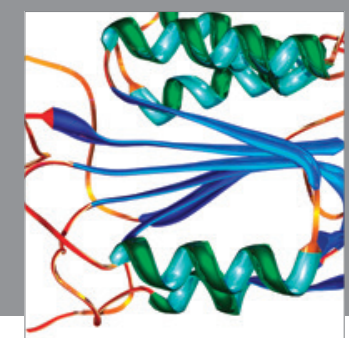

Disease Markers
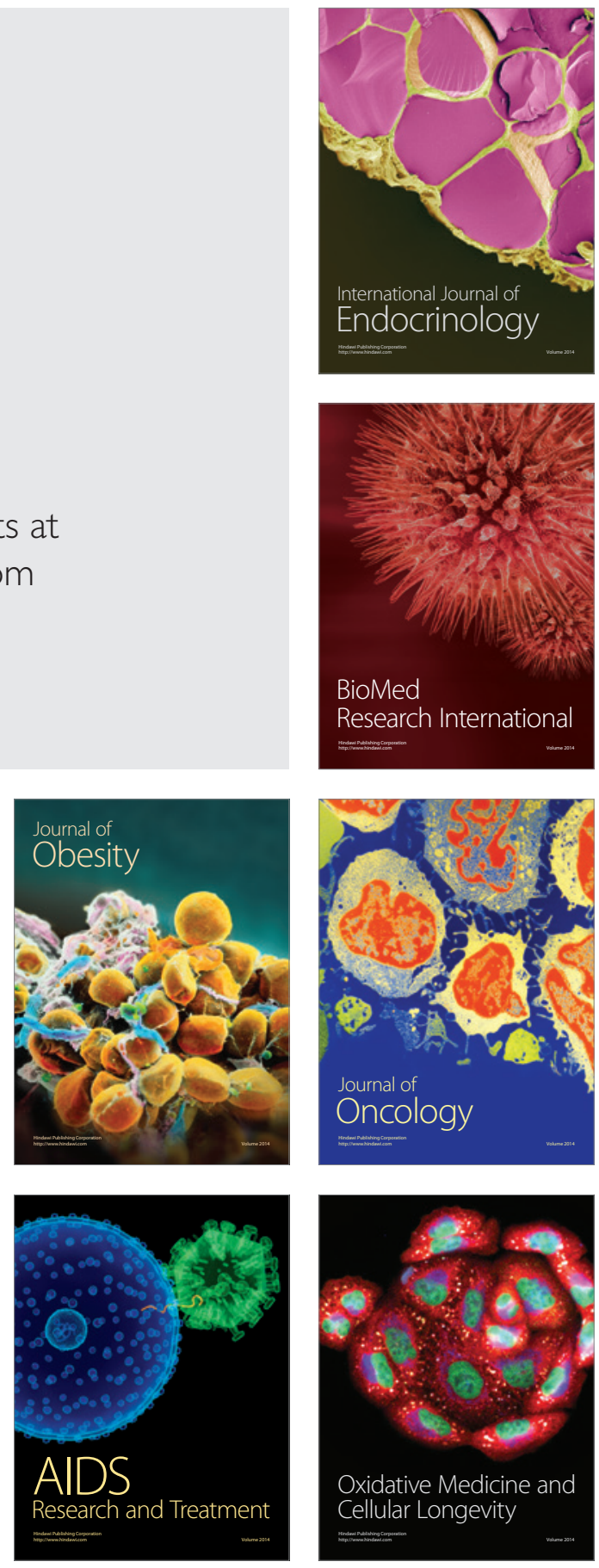